\title{
Simulasi Potensi Gerakan Tanah Lereng Alami Akibat Perubahan Tata Guna Lahan Periode Tahun 2013 - 2020 Wilayah Kecamatan Cimenyan, Kabupaten Bandung, Provinsi Jawa Barat
}

\author{
Fachrul Rozy Elba Ansofa*, Yunus Ashari \\ Prodi Teknik Pertambangan, Fakultas Teknik, Universitas Islam \\ Bandung, Indonesia. \\ *fachrulrozyea9@gmail.com, yunus_ashari@unisba.ac.id
}

\begin{abstract}
Natural disasters caused by geological aspects are difficult to predict when and where the disaster will occur because many factors can trigger a disaster. In West Java Province there have been around 64 incidents of landslides that harm humans. The Cimenyan sub-district is dominated by the topography of the Slope / Ridge area and the land use of the Forest Area with an altitude of 946 meters above sea level. In Cimenyan district, land cover changes from green open spaces to built spaces can have an impact on slope stability. Changes in land cover in conservation areas into built-up areas can cause floods, erosion, landslides, drought, and reduced soil fertility. So in general, these conditions can have a high potential level of vulnerability or vulnerability to landslide events. The potential ground movement zone is formed in case 3 conditions in the northeastern part of Cimenyan village covering the coordinates of $797000 \mathrm{me}, 9244500 \mathrm{mn}$ to $798000 \mathrm{me}, 9243500 \mathrm{mn}$. With a value of 1.201 safety factor decreased in case 4 conditions to 1.133 . Furthermore, if it is simulated in case 5 conditions, the value of the safety factor becomes 1.070 and another potential ground movement zone appears in the eastern part of Cimenyan village covering the coordinates of $795500 \mathrm{me}, 9241500 \mathrm{mn}$ to $796000 \mathrm{me}, 9241000 \mathrm{mn}$ with a safety factor value of 1.235 .
\end{abstract}

Keywords: Landslide, Slope, Soil.

Abstrak. Bencana alam yang disebabkan oleh aspek geologi sulit untuk diprediksi waktu dan lokasi bencana tersebut akan terjadi, karena banyak faktor yang dapat memicu terjadinya bencana. Di Provinsi Jawa Barat telah terjadi sekitar 64 kejadian bencana gerakan tanah yang merugikan manusia. Kecamatan Cimenyan didominasi oleh topografi wilayah Lereng/Punggung Bukit dan tata lahan Kawasan Hutan dengan ketinggian 946 meter dari permukaan laut. Di Kecamatan Cimenyan perubahan tutupan lahan dari ruang terbuka hijau menjadi ruang terbangun dapat berdampak pada kestabilan lereng. Perubahan tutupan lahan pada kawasan konservasi menjadi kawasan terbangun dapat menimbulkan bencana banjir, erosi, tanah longsor, kekeringan dan berkurangnya kesuburan tanah. Sehingga secara umum kondisi tersebut dapat mempunyai potensi tingkat kerawanan atau kerentanan kejadian bencana longsor yang tinggi. Zona potensi gerakan tanah terbentuk pada kondisi case 3 di Bagian Timurlaut Desa Cimenyan meliputi kordinat 797000 mE, 9244500 mN hingga $798000 \mathrm{mE}, 9243500 \mathrm{mN}$. Dengan nilai faktor keamanan 1,201 mengalami penurunan pada kondisi case 4 menjadi 1,133 . Selanjutnya apabila disimulasikan pada kondisi case 5 nilai faktor keamanan menjadi 1,070 dan muncul daerah zona potensi gerakan tanah lainnya di bagian timur Desa Cimenyan meliputi kordinat $795500 \mathrm{mE}, 9241500 \mathrm{mN}$ hingga $796000 \mathrm{mE}, 9241000 \mathrm{mN}$ dengan nilai faktor keamanan 1,235 .

Kata Kunci: Longsor, Lereng, Tanah. 


\section{A. Pendahuluan}

Bencana alam yang disebabkan oleh aspek geologi seperti tanah longsor/gerakan tanah sulit untuk diprediksi waktu dan lokasi bencana tersebut akan terjadi, karena banyak aspek yang dapat memicu terjadinya bencana gerakan tanah meliputi faktor alam dan akibat aktivitas. Pusat Vulkanologi dan Mitigasi Bencana Geologi mencatat pada tahun 2012 telah terjadi 127 kejadian gerakan tanah yang merugikan di Indonesia, oleh karena itu perlu adanya suatu kegiatan kajian pemetaan zona potensi gerakan tanah sebagai upaya pencegahan dalam penanggulangan bencana yang belum terjadi dan dapat meminimalisir kerugian infrastruktur dan korban jiwa.

Di Kecamatan Cimenyan perubahan tutupan lahan dari ruang terbuka hijau menjadi ruang terbangun, meliputi permukiman, area komersial, fasilitas pendidikan, dan infrastruktur dapat berdampak pada kestabilan lereng. Perubahan tutupan lahan pada kawasan konservasi menjadi kawasan terbangun dapat menimbulkan bencana banjir, erosi, tanah longsor, kekeringan dan berkurangnya kesuburan tanah. Sehingga secara umum kondisi tersebut mempunyai potensi tingkat kerawanan kejadian bencana longsor yang tinggi.

Tingkat kerapatan dan keragaman dari aspek geologi maupun kemiringan lereng cukup tinggi. Dari aspek geologi, wilayah Kabupaten Cimenyan memiliki karakteristik yang cenderung khas yang didominasi oleh batuan hasil gunung api yaitu Breksi Gunung api, Lahar dan Lava berselang-seling dan aspek kemiringan lereng cenderung terjal. Berdasarkan kondisi dan aspek tersebut menjadikan wilayah Kecamatan Cimenyan rawan terjadi bencana gerakan tanah dan cocok dilakukan pemetaan potensi gerakan tanah terkhusus pada aspek tutupan lahan dari lereng.

\section{B. Metodologi Penelitian}

\section{Metode Pengambilan Data}

Metode pengambilan data pada penelitian ini secara garis besar terbagi menjadi 2 metode, yaitu

1. Pengambilan Data Primer

Pengambilan data primer adalah metode pengambilan data secara aktual dan langsung di lapangan. Data primer meliputi data Nilai Kohesi Tanah, Nilai Massa Jenis Tanah, Nilai Sudut Geser Tanah dan hasil pemetaan lereng alami langsung yaitu Ketebalan Tanah dan Kemiringan Lereng.

2. Pengambilan Data Sekunder

Pengambilan data sekunder adalah metode pengambilan data dengan cara mengumpulkan studi literatur yang berkaitan dengan kebutuhan pengolahan data serta dapat dipertanggungjawabkan. Data sekunder meliputi foto udara dan citra satelit, peta topografi, peta geologi, peta tata guna lahan, dan data sekunder pendukung lainya.

\section{Teknik Pengolahan Data}

Teknik pengolahan data pada penelitian ini, yaitu teknik langsung. Teknik Langsung adalah teknik pengolahan data hasil pemetaan langsung zona kerentanan gerakan tanah di lapangan. Teknik ini meliputi penelitian gerakan tanah langsung di lapangan, mempelajari sifat fisik dan mekanik batuan/tanah hasil sampel dari pengujian di laboratorium, melakukan analisis kestabilan lereng, dan menganalisis tingkat kerentanan gerakan tanah.

\section{Teknik Analisis Data}

1. Analisis Pemetaan Tidak Langsung

Analisis tidak langsung merupakan analisis dari hasil pengolah data sekunder.

2. Analisis Pemetaan Langsung

Analisis pemetaan langsung merupakan analisis dari hasil pengolahan data sekunder.

3. Analisis Data Simulasi Model

Analisis data simulasi model bertujuan untuk membuat model konstruksi matematika untuk menduga karakteristik masalah dengan menggunakan model yang diajukan. Teknik ini menyesuaikan Initial Condition dengan simulasi sebab akibat pada periode yang ingin ditentukan. 


\section{Hasil Penelitian dan Pembahasan \\ Pengamatan Lokasi Penelitian}

Titik pengamatan lokasi penelitian terbagi menjadi 20 titik yang tersebar di Kecamatan Cimenyan. Berikut koordinat titik pengamatan dan data pengukuran ketebalan tanah yang didapatkan dari pengamatan lapangan, seperti gambar berikut.

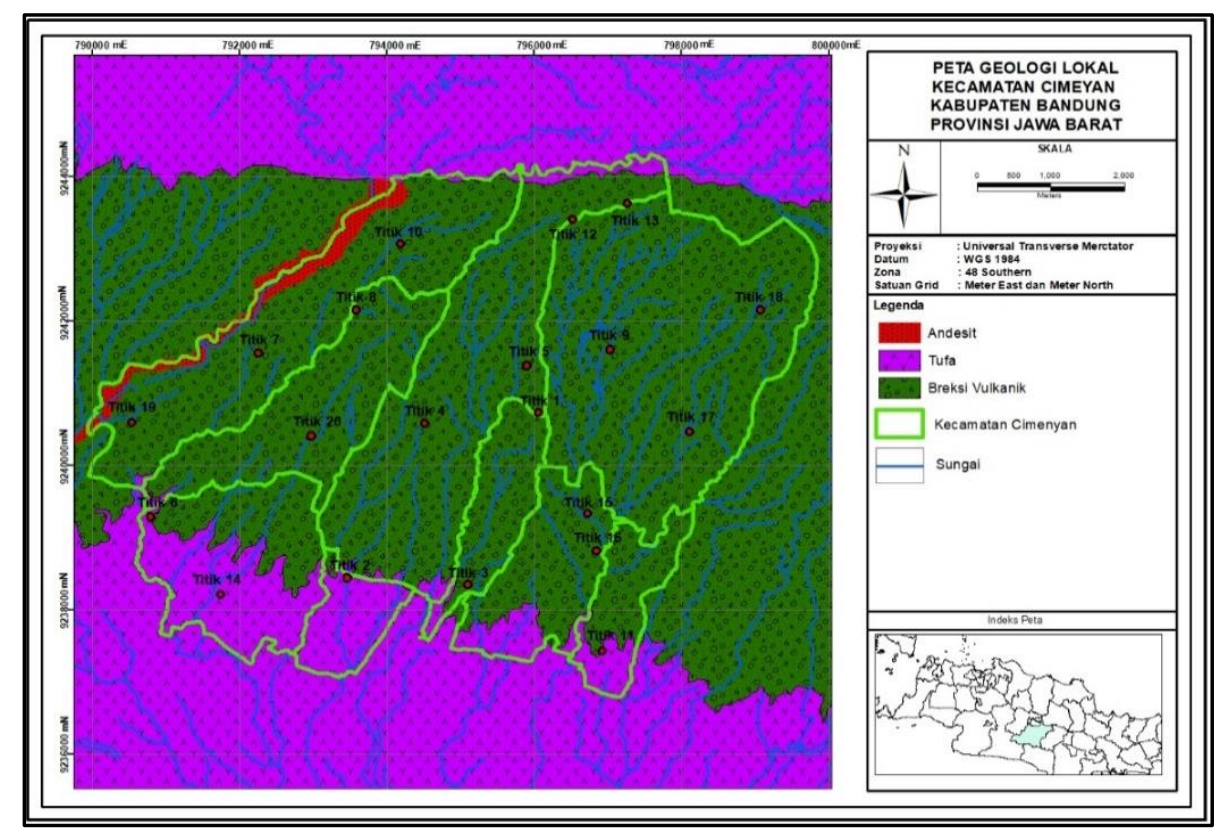

Gambar 1. Titik Pengambilan Sampel Pada Kecamatan Cimenyan

Dari hasil pengambilan data lapangan dan pengumpulan data sekunder selanjutnya dilakukan pengolahan data yang bertujuan agar dapat memenuhi output data yang diinginkan. Output data yang dibutuhkan yaitu :

1. Nilai Massa Jenis Tanah;

2. Nilai Kohesi Tanah;

3. Nilai Sudut Geser Dalam Tanah;

4. Kemiringan Lereng;

5. Ketebalan Tanah;

6. Daerah Aktual Tutupan Lahan.

\section{Tata Guna Lahan}

Data citra satelit dibutuhkan untuk menginterpretasi tutupan lahan di Kecamatan Cimenyan pada periode tahun 2013 - 2020. Interpretasi citra satelit menggunakan Citra Landsat 8 OLI (Operational Land Imager) yang mengorbit dari bulan November 2012 sampai dengan saat ini sehingga data hasil perekaman terakhir. Citra Landsat 8 yang dipilih yaitu pada level 1, agar didapatkan analisis RGB yang sesuai dengan kebutuhan interpretasi tutupan lahan meliputi Tutupan Lahan Hutan, Tutupan Lahan Perkebunan/Lahan Tanah dan Tutupan Lahan Permukiman. 


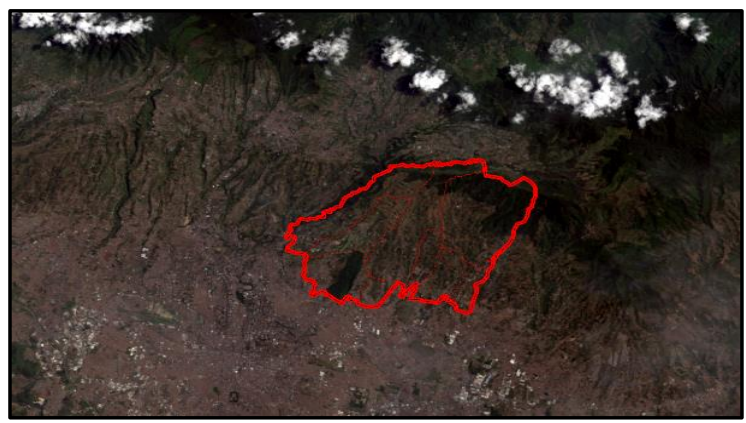

Gambar 2. Citra Satelit Kecamatan Cimenyan (Google Earth, 2020)

Agar mempermudah proses interpretasi dipilih penutupan awan pada citra $<10 \%$ dengan kualitas multispektral dan resolusi yang baik. Pada kondisi penutupan awan $>10 \%$ akan membuat perekaman tertutup awan dan kabut yang menyebabkan terganggunya gambar yang akan diinterpretasi. Data citra satelit diakses dan diunduh di situs http://www.earthexplorer.usgs.gov

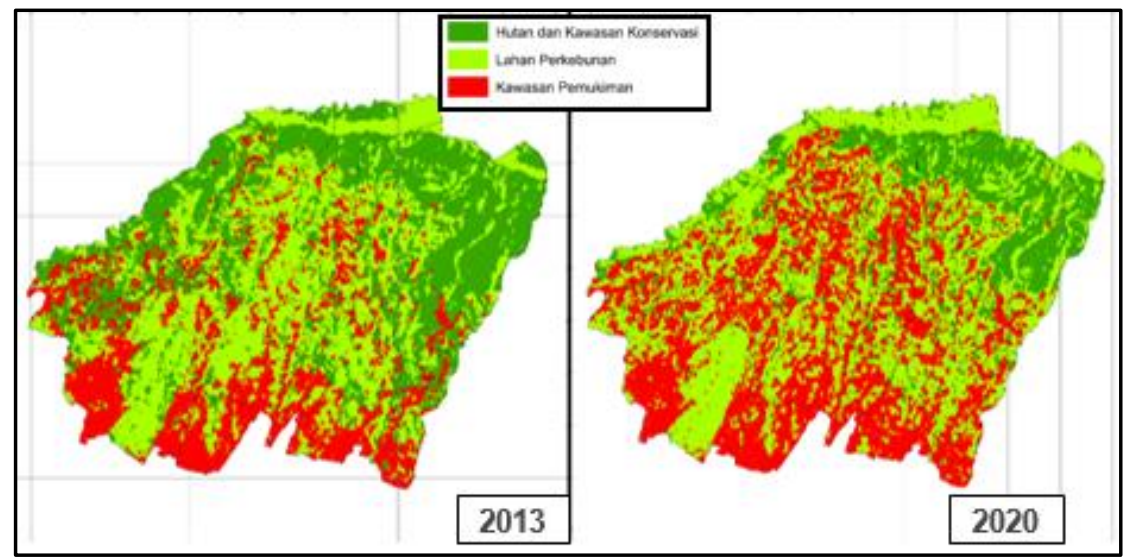

Gambar 3. Perubahan Tutupan Lahan Tahun 2013 dan Tahun 2020

Klasifikasi Hutan dan Kawasan Konservasi meliputi kawasan hutan, kawasan konservasi, dan kawasan dengan kerapatan tumbuhan yang cenderung tinggi. Pada klasifikasi Lahan Perkebunan meliputi lahan tanah kosong, lahan perkebunan, ladang, dan kawasan dengan kerapatan tumbuhan yang cenderung rendah atau tidak lebat. Pada Kawasan Permukiman meliputi komplek perumahan, rumah, sekolah, jalan, dan infrastruktur bangunan.

\section{Perhitungan Nilai Faktor Keamanan}

Berikut hasil penelitian dari rancangan Simulasi Potensi dari Kecamatan Cimenyan dengan konsentrasi luasan penelitian $(10.500 \mathrm{~m} \mathrm{X} 10.500 \mathrm{~m})$ terdiri dari $21 \mathrm{X} 21$ grid. Dari hasil pengolahan data Massa Jenis Tanah, Nilai Kohesi Tanah, Nilai Sudut Geser Tanah, Kemiringan Lereng dan Tinggi Lereng dengan cara metode perhitungan teknik Iterasi Pemecahan data Beda Hingga (Finite Different). Dalam penentuan faktor keamanan, metode pendekatan yang dipakai dengan metode analitik geoteknik yaitu metode yang dikemukakan oleh Hoek and Bray, 1974. Input yang dibutuhkan berasal dari pengolahan data yang telah dijabarkan sebelumnya. Input data yang diperlukan meliputi Massa Jenis Tanah, Kohesi Tanah, Sudut Geser Dalam Tanah, Kemiringan Lereng, dan Tinggi Lereng untuk menghasilkan output data berupa nilai Faktor Keamanan. Agar mempermudah proses simulasi, maka perlu dirancang suatu sistem perhitungan nilai Faktor Keamanan yang berdasar dari kelima Case di Chart Hoek And Bray, 1974. Sistem perhitungan nilai Faktor Keamanan, menggunakan perangkat lunak Microsoft Office Excel. 


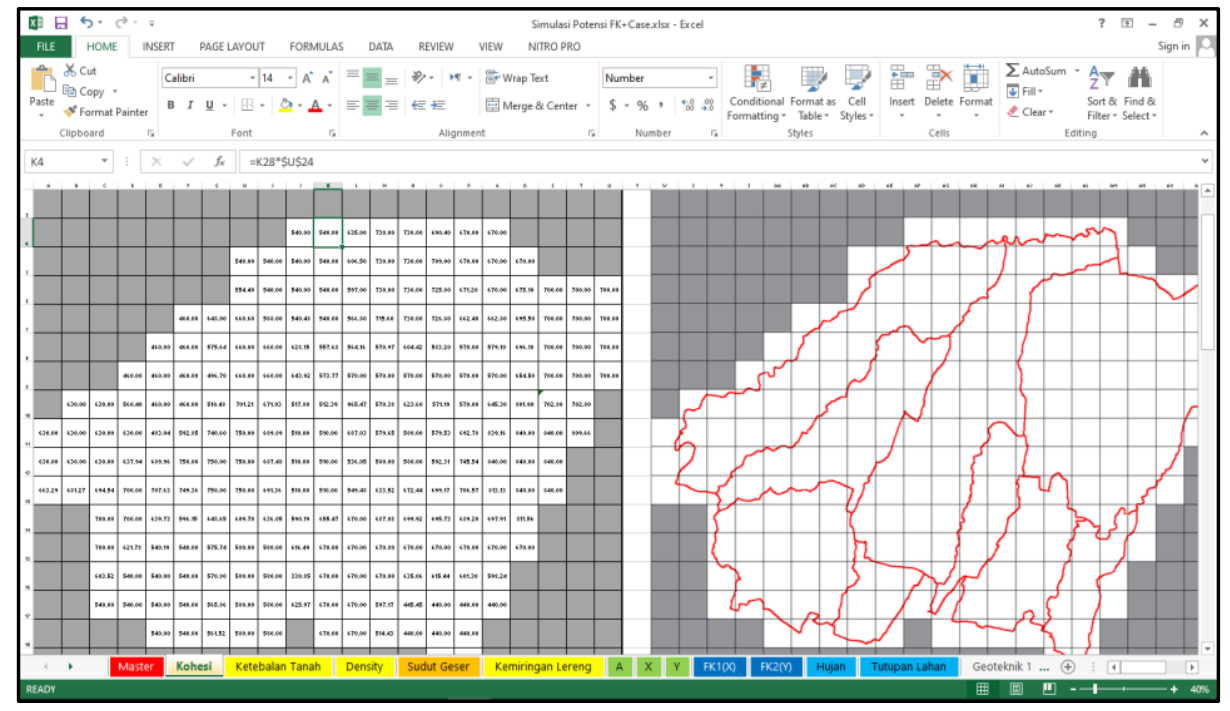

Gambar 4. Simulasi Faktor Keamanan Pada Perangkat Lunak Microsoft Excel

\section{Hasil Perhitungan Faktor Keamanan}

Berikut hasil simulasi perhitungan faktor keamanan pada 5 keadaan Case yang dikemukakan oleh Hoek And Bray, 1974.

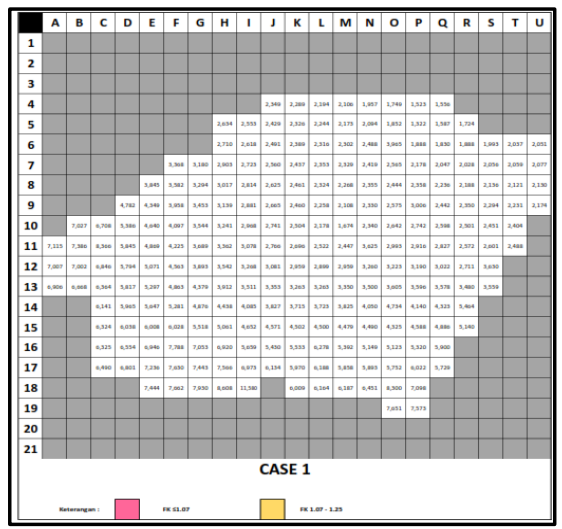

Gambar 5. Simulasi Keadaan Case 1

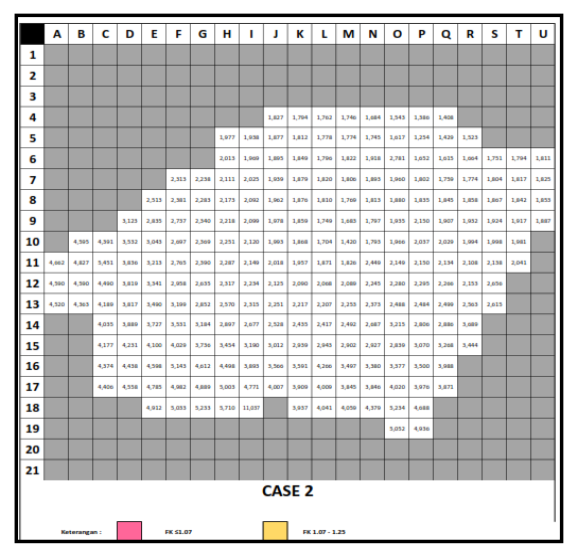

Gambar 6. Simulasi Keadaan Case 2 


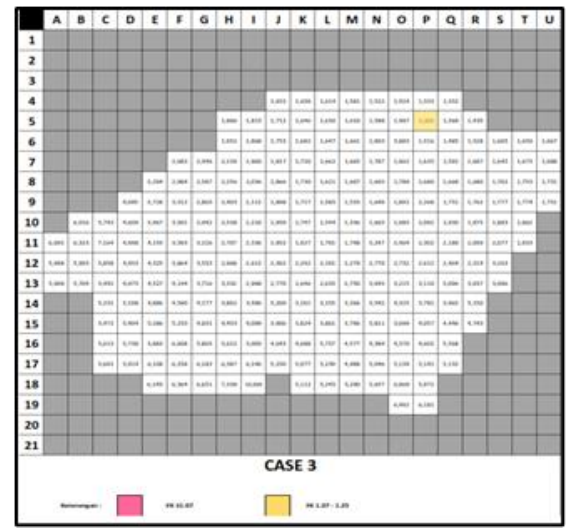

Gambar 7. Simulasi Keadaan Case 3

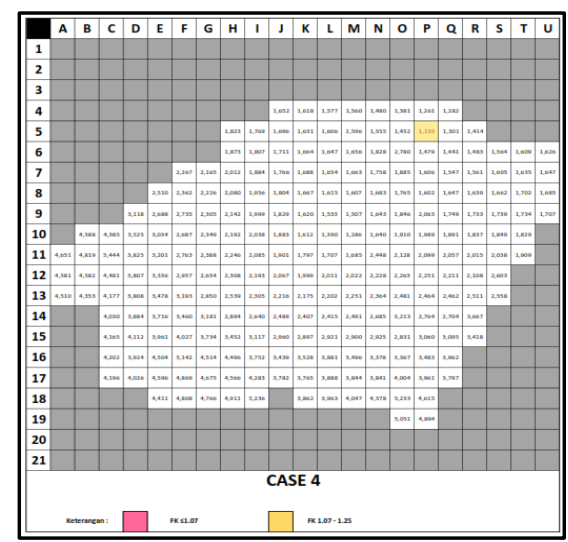

Gambar 8. Simulasi Keadaan Case 4

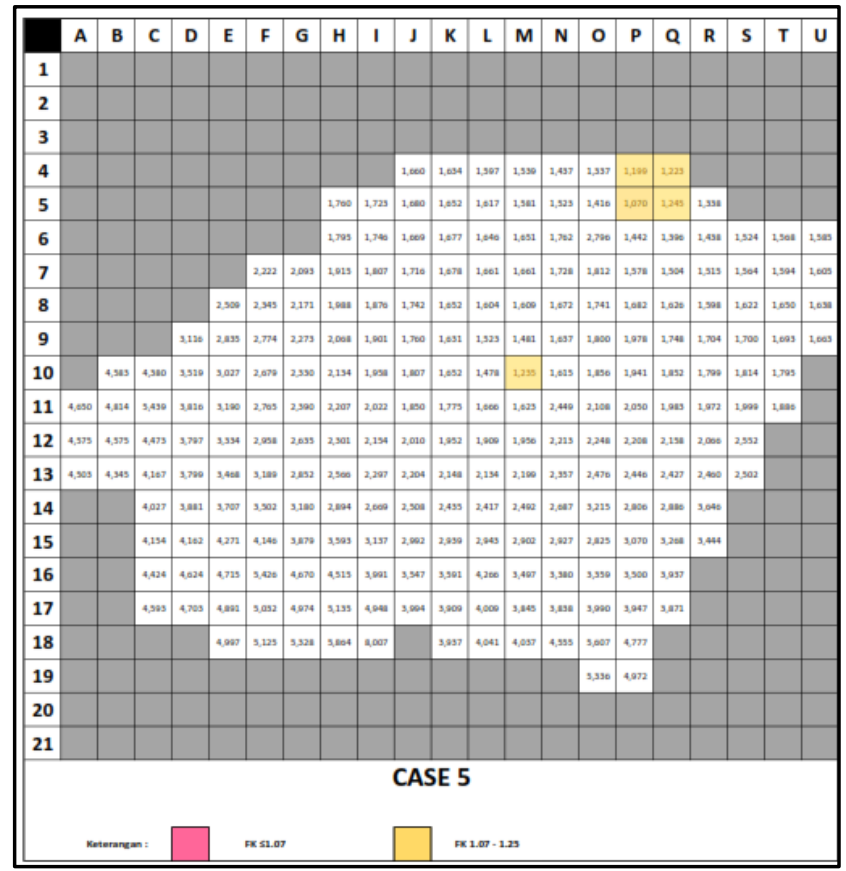

Gambar 9. Simulasi Keadaan Case 5 


\section{Analisis Zona Kerentanan Gerakan Tanah}

Zona kerentanan gerakan tanah didasari oleh nilai faktor keamanan yang didapatkan. Kriteria faktor keamanan menggunakan kriteria dari Bowles, 1991. Berikut kriteria Bowles, 1991 yaitu

Tabel 1. Kriteria Faktor Keamanan

\begin{tabular}{|c|c|c|}
\hline No & Nilai Faktor Keamanan & Kategori \\
\hline 1 & $<1.07$ & Labil \\
\hline 2 & $1.07-1.25$ & Kritis \\
\hline 3 & $>1.25$ & Stabil \\
\hline
\end{tabular}

Sumber: (Bowles, 1991)

Secara umum pada daerah Kecamatan Cimenyan didominasi oleh kategori stabil dan beberapa titik berkembang menjadi kategori kritis seiring dengan meningkatnya keadaan case yang dipakai. Pada Kecamatan Cimenyan, daerah yang awalnya stabil mulai muncul grid labil di grid (P5) pada keadaan Case 3 yaitu keadaan setengah jenuh dan setengah kering dengan nilai 1,201. Kemudian ketika disimulasikan menjadi keadaan Case 4, grid (P5) mengalami penurunan nilai menjadi 1,133. Dan setelah disimulasikan menjadi keadaan Case 5, grid (P5) memiliki nilai faktor keamanan menjadi 1,070. Selain itu pada keadaan Case 5 mulai banyak grid yang menjadi kategori kritis, yaitu pada grid (P4) dengan nilai 1,199 ; grid (Q4) dengan nilai 1,223; grid (Q5) dengan nilai 1,245; dan grid (M10) dengan nilai 1,235. Secara garis besar daerah labil terbentuk dan berkembang di daerah Utara hingga Timur Laut Kecamatan Cimenyan.

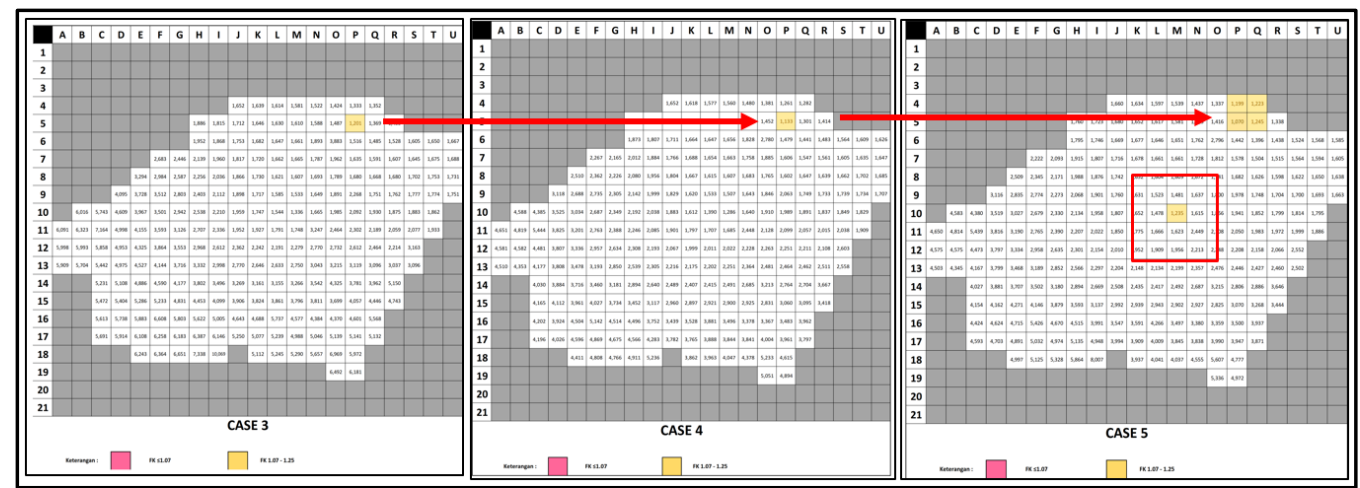

Gambar 10. Simulasi Perubahan Nilai Faktor Keamanan Pada Case 3, Case 4 dan Case 5

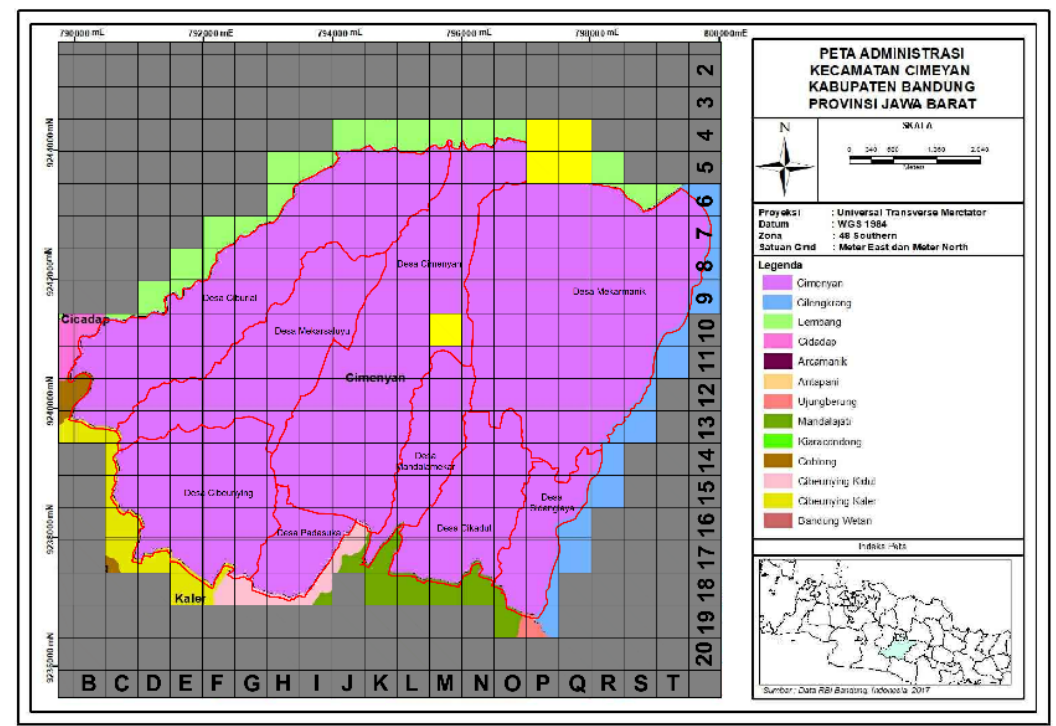

JRTP is licensed under Creative Commons Attribution-

NonCommercial-ShareAlike 4.0 International License. 
Gambar 11. Overlay Peta Administrasi Daerah dan Hasil Simulasi Faktor Keamanan

\section{Hubungan Zona Kerentanan Gerakan Tanah dan Air}

Semakin jenuh keadaan lereng, maka nilai faktor keamanan akan semakin kecil. Berikut nilai rata-rata faktor keamanan yang dihasilkan dari setiap case.

Grafik 1. Nilai Rata- Rata Setiap Case

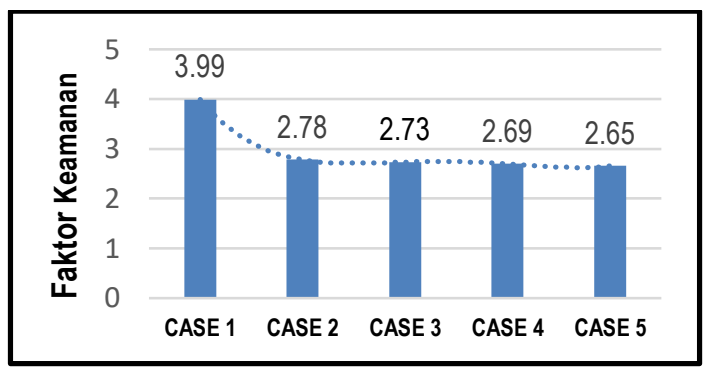

Berdasarkan grafik di atas, dapat ditarik informasi bahwa laju penurunan faktor keamanan dari Case 1 ke Case 2 sebesar 30,33\% dan dari Case 2, Case 3, Case 4 hingga Case 5 nilai faktor keamanan mengalami penurunan yang tidak signifikan. Perbedaan antara setiap Case yaitu kondisi air yang ada pada lereng yang disesuaikan dengan berbagai kondisi. Pada case 1 lereng disimulasikan kering, sedangkan pada case lainya lereng disimulasikan sudah jenuh. Sehingga dapat disimpulan bahwa kondisi lereng yang jenuh bisa mengakibatkan penurunan nilai faktor keamanan yang cukup drastis dan signifikan. Lereng yang jenuh biasanya didominasi oleh faktor air dari hujan yang mengisi lereng sehingga lereng menjadi berat. Sehingga hujan menjadi faktor utama yang dapat menyebabkan terjadinya longsor. Berikut tabel Kategori Kriteria Penilaian Curah Hujan

Tabel 2. Kriteria Faktor Keamanan

\begin{tabular}{|c|c|c|}
\hline No & $\begin{array}{c}\text { Besar Curah Hujan } \\
(\mathbf{m m} / \text { Hari })\end{array}$ & Kategori \\
\hline 1 & $<2.778$ & Sangat Rendah \\
\hline 2 & $2.78-4.167$ & Rendah \\
\hline 3 & $4.167-5.556$ & Sedang \\
\hline 4 & $5.556-6.944$ & Tinggi \\
\hline 5 & $>6.944$ & Sangat Tinggi \\
\hline
\end{tabular}

Sumber : (Taufik, 2008)

Dari kriteria tersebut, dapat disimpulkan bahwa nilai curah hujan terbagi atas 5 kategori, yaitu kategori Sangat Rendah, Rendah, Sedang, Tinggi dan Sangat Tinggi. Kelima kategori ini diasumsikan sebagai kondisi lereng (Case) yang dilakukan simulasi sebagai penggambaran kondisi dilapangan.

Tabel 3. Asumsi Kriteria Penilaian Curah Hujan dan Case

\begin{tabular}{|c|c|}
\hline Kategori & Case \\
\hline Sangat Rendah & 1 \\
\hline Rendah & 2 \\
\hline Sedang & 3 \\
\hline Tinggi & 4 \\
\hline Sangat Tinggi & 5 \\
\hline
\end{tabular}

Dari nilai faktor keamanan Hoek and Bray, memiliki 5 keadaan yang penentuannya berdasarkan keadaan lereng. Untuk itu perlu diasumsikan dan dilakukan analisis balik untuk mengetahui tipikal hujan yang akan menyebabkan terjadinya longsor yang sangat mempengaruhi nilai faktor keamanan. Pada analisis balik, contoh model lereng yang dipakai adalah keadaan Case 5 dengan intensitas curah hujan $>6.944 \mathrm{~mm} /$ hari atau dibulatkan menjadi 
$7 \mathrm{~mm} /$ hari. Sehingga dapat disimpulkan apabila di daerah Kecamatan Cimenyan terjadi hujan dengan intensitas $7 \mathrm{~mm} /$ hari akan menjadikan nilai faktor keamanan yang digunakan sebagai kondisi nyata kondisi lereng menjadi case 5 . Intensitas hujan $7 \mathrm{~mm} /$ hari, menjadi patokan utama dari hujan yang terjadi, sehingga apabila angka $7 \mathrm{~mm} /$ hari bisa dijabarkan menjadi intensitas hujan sebesar :

Tabel 4. Penjabaran Nilai Intensitas Hujan $7 \mathrm{~mm} / \mathrm{hari}$

\begin{tabular}{|c|c|}
\hline $\begin{array}{c}\text { Intensitas } \\
(\mathbf{m m})\end{array}$ & $\begin{array}{c}\text { Durasi } \\
(\mathbf{j a m})\end{array}$ \\
\hline 1 & 7,00 \\
\hline 2 & 3,50 \\
\hline 3 & 2,3 \\
\hline 4 & 1,25 \\
\hline 5 & 1,4 \\
\hline 6 & 1,67 \\
\hline 7 & 1,00 \\
\hline 8 & 0,87 \\
\hline
\end{tabular}

Sehingga dapat disimpulkan bahwa hujan dengan intensitas $1 \mathrm{~mm}$ selama 7 jam, akan setara dengan juga yang memiliki intensitas $8 \mathrm{~mm}$ selama 52,5 menit. Artinya apabila terjadi hujan seperti tersebut akan terjadi Case 5 dan banyak grid yang menjadi kategori labil, yaitu pada grid (P5) dengan nilai 1,071; grid (P4) dengan nilai 1,199; grid (Q4) dengan nilai 1,223; grid (Q5) dengan nilai 1,245; dan grid (M10) dengan nilai 1,235. Dan daerah pada grid tersebut masuk kedalam Zona Kerentanan Gerakan Tanah.

\section{Hubungan Zona Kerentanan Gerakan Tanah Dan Tata Guna Lahan}

Dalam simulasi potensi gerakan tanah lereng alami ini, berfokus pada keadaan lereng akibat perubahan tata guna lahan yang bisa saja terjadi bencana longsor yang dapat memakan korban jiwa, jika dilihat dari Analisis Zona Kerentanan Gerakan Tanah dan Hubunganya dengan air, dapat disimpulkan bahwa pada pada grid (P5) dengan nilai 1,071; grid (P4) dengan nilai 1,199 ; grid (Q4) dengan nilai 1,223; grid (Q5) dengan nilai 1,245; dan grid (M10) dengan nilai 1,235 merupakan daerah yang sangat rawan. Setelah dihubungkan dengan tata guna lahan, berikut daerah tata guna lahan permukiman yang berpotensi labil, yaitu :

Tabel 5. Grid dan Tata Guna Lahan Permukiman

\begin{tabular}{|c|c|}
\hline Grid & $\begin{array}{c}\text { Luasan Tata Guna Lahan } \\
\text { Permukiman } \\
\left(\mathbf{m}^{\mathbf{2}} \mathbf{)}\right.\end{array}$ \\
\hline P4 & 0 \\
\hline P5 & $5.934,77$ \\
\hline Q4 & $3.438,45$ \\
\hline Q5 & 195,46 \\
\hline M10 & $161.559,08$ \\
\hline Total & $171,127.76$ \\
\hline
\end{tabular}

Bentuk tata guna lahan sangatlah mempengaruhi nilai faktor keamanan yang berkaitan dengan air hujan yang akan masuk ke dalam lereng tanah dan menjadi beban untuk lereng tersebut. Dalam interpretasi tata guna lahan, klasifikasi dijadikan 3 yang meliputi Hutan dan Kawasan Konservasi, Lahan Perkebunan dan Kawasan Permukimandi Kecamatan Cimenyan. 


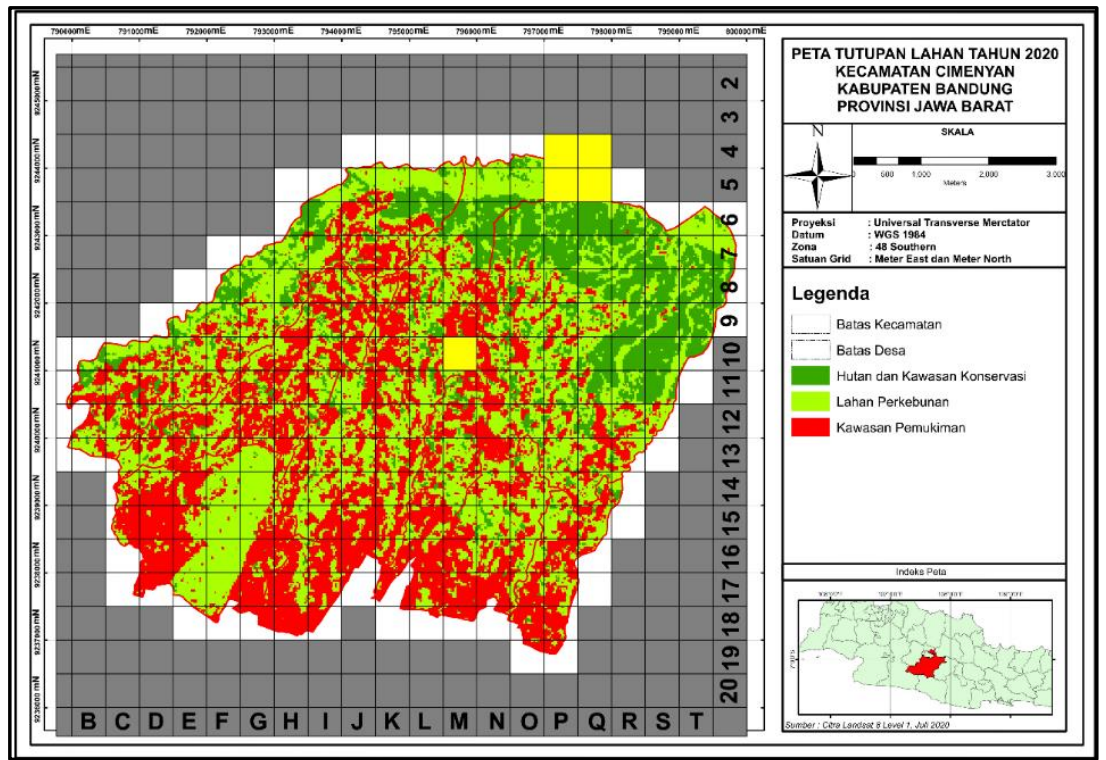

Gambar 12. Overlay Peta Tutupan Lahan Tahun 2020 dan Hasil Simulasi Faktor Keamanan

Tata guna lahan merupakan hal penting dalam mengetahui potensi kelongsoran pada suatu daerah. Dari analisis citra satelit, didapatkan luasana tata guna lahan sebagai berikut :

Tabel 6. Perubahan Luas Tutupan Lahan Daerah Penelitian

\begin{tabular}{|c|c|c|c|c|}
\hline Tahun & $\begin{array}{c}\text { Hutan dan } \\
\text { Kawasan } \\
\text { Konservasi } \\
\left(\mathbf{m}^{2}\right)\end{array}$ & $\begin{array}{c}\text { Lahan } \\
\text { Perkebunan } \\
\left(\mathbf{m}^{2}\right)\end{array}$ & $\begin{array}{c}\text { Kawasan } \\
\text { Permukiman } \\
\left(\mathbf{m}^{2}\right)\end{array}$ & $\begin{array}{l}\text { Total Luas } \\
\quad\left(\mathbf{m}^{2}\right)\end{array}$ \\
\hline 2013 & $18,085,600$ & $19,789,200$ & $10,159,100$ & $48,033,900$ \\
\hline 2014 & $17,441,100$ & $20,047,725$ & $10,545,075$ & $48,033,900$ \\
\hline 2015 & $16,700,250$ & $19,967,925$ & $11,365,725$ & $48,033,900$ \\
\hline 2016 & $16,663,075$ & $16,313,800$ & $15,057,025$ & $48,033,900$ \\
\hline 2017 & $14,925,600$ & $16,737,775$ & $16,370,525$ & $48,033,900$ \\
\hline 2018 & $14,195,325$ & $17,186,975$ & $16,651,600$ & $48,033,900$ \\
\hline 2019 & $9,851,400$ & $21,549,150$ & $16,633,350$ & $48,033,900$ \\
\hline 2020 & $8,313,750$ & $22,123,125$ & $17,597,025$ & $48,033,900$ \\
\hline
\end{tabular}

Dari tabel tersebut dapat disimpulkan bahwa tata guna lahan hutan dan kawasan konservasi setiap tahunya mengalami konstan penurunan, dan selama 7 tahun terakhir mengalami penurunan hingga 54,03\% dari keadaan di tahun 2013.

Grafik 2. Laju Penurunan Luasan Wilayah Hutan Dan Kawasan Konservasi

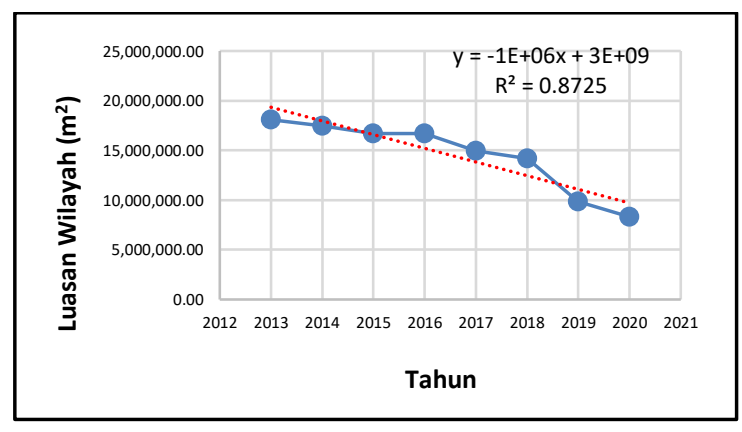

Pada tata guna lahan perkebunan mengalami fluktuasi perubahan pada setiap tahunya, perubahan tata guna lahan perkebunan cenderung dinamis. 
Grafik 3. Laju Perubahan Wilayah Perkebunan

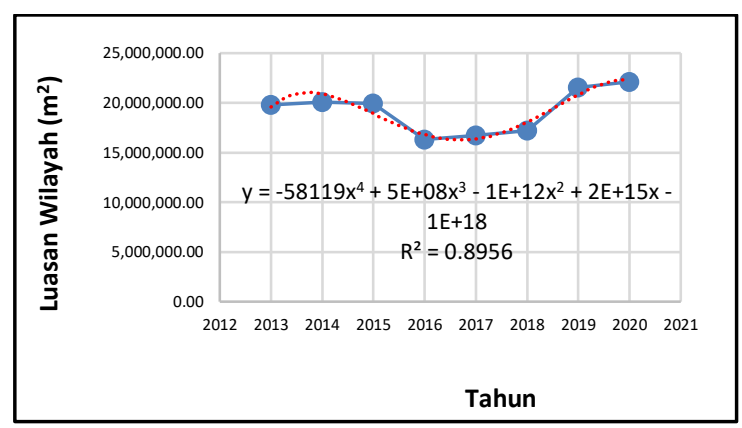

Pada tata guna lahan Kawasan Permukiman setiap tahunya mengalami konstan kenaikan, dan selama 7 tahun terakhir mengalami kenaikan hingga 73,21\% dari keadaan di tahun 2013.

Grafik 4. Laju Kenaikan Luasan Wilayah Permukiman

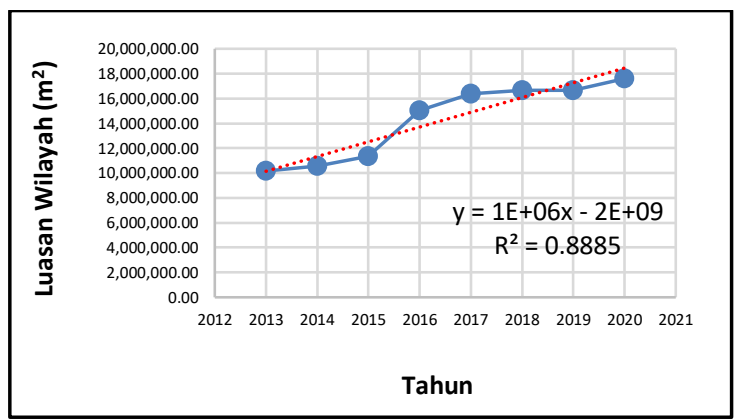

Apabila berfokus pada laju kenaikan luasan kawasan permukiman, maka dapat disimulasikan bahwa :

$$
\left.\mathrm{y}=\left(1.10^{6}(X)-2.10\right)^{9}\right) \times 0.8885
$$

Tabel 7. Prediksi Luasan Kawasan Permukiman Kecamatan Cimenyan

\begin{tabular}{|c|c|}
\hline Tahun & $\begin{array}{c}\text { Prediksi Luasan Kawasan } \\
\text { Permukiman } \\
\left(\mathbf{m}^{\mathbf{}}\right)\end{array}$ \\
\hline 2025 & $22,212,500.000$ \\
\hline 2030 & $26,655,000.000$ \\
\hline 2035 & $31,097,500.000$ \\
\hline 2040 & $35,540,000.000$ \\
\hline 2045 & $39,982,500.000$ \\
\hline 2050 & $44,425,000.000$ \\
\hline
\end{tabular}

\section{Kesimpulan}

Berdasarkan hasil penelitian dan pembahasan yang telah diuraikan pada bab sebelumnya, maka dapat disimpulkan sebagai berikut.

1. Zona potensi gerakan tanah pada Kecamatan Cimenyan yaitu pada daerah Timur Laut Desa Cimenyan yang ditunjukan pada grid (p4), (p5), (q4) dan (q5). Selain itu di bagian timur Desa Cimenyan juga muncul daerah yang rawan terjadi potensi gerakan tanah;

2. Pengaruh faktor tata guna lahan permukiman yang berpotensi labil, yaitu pada daerah Desa Cimenyan. Di Desa Cimenyan total daerah permukiman berpotensi longsor yaitu $171,127.76 \mathrm{~m} 2$;

3. Upaya mitigasi bencana dapat dihindari dengan penentuan lokasi yang rawan terjadi bencana longsor. Jika di Kecamatan Cimenyan terus terjadi perubahan lahan yang tadinya kawasan hutan dan konservasi serta lahan perkebunan menjadi kawasan 
permukiman maka potensi terjadinya bencana longsor yang dapat merugikan manusia akan semakin tinggi. daerah yang saat ini (tahun 2020) masuk kedalam daerah rawan longsor yaitu pada bagian timurlaut desa Cimenyan koordinat $797000 \mathrm{mE}, 9244500 \mathrm{mN}$ hingga $798000 \mathrm{mE}, 9243500 \mathrm{mN}$. dan pada bagian timur desa Cimenyan meliputi koordinat $795500 \mathrm{mE}, 9241500 \mathrm{mN}$ hingga $796000 \mathrm{mE}, 9241000 \mathrm{mN}$.

\section{Acknowledge}

Terima Kasih kepada Bapak Dr. Ir. Yunus Ashari, M. T. yang telah memberikan banyak ide, arahan dan bimbingan dalam menyelesaikan penelitian ini agar dapat bermanfaat khususnya kepada masyarakat Kecamatan Cimenyan, Kabupaten Bandung, Provinsi Jawa Barat.

\section{Daftar Pustaka}

[1] Aqnes Arwidya, Monica. 2014. Kesiapan Masyarakat Dalam Menghadapi Bencana Tanah Longsor Di Kecamatan Kaloran Kabupaten Temanggung. Skripsi. Jurusan Geografi. FIS. UNNES.

[2] Badan Pusat Statistik. 2018. Kecamatan Cimenyan Dalam Angka. Kabupaten Bandung: Badan Pusat Statistik Kabupaten Bandung

[3] Gunadi, Sunarto dkk. 2004. Tingkat Bahaya Longsor di Kecamatan Samigaluh dan Sekitarnya Kabupaten Kulonprogo DIY. Kongres MKTI Ke V dan Seminar Nasional Degradasi Hutan dan Lahan. Yogyakarta. UGM.

[4]Rohman, Rizka Zaenur. 2013. Analisis Tingkat Kerawanan Longsorlahan dan Mitigasi Bencana di Kecamatan Karangsambung Kabupaten Kebumen. Skripsi. FKIP. UNS.

[5]Taufik, H.P. dan Suryadi. 2008. Landslide Risk Spatial Modeling Using Geographical Information System. Tutorial Landslide. Laboratorium Sistem Informasi Geografis. Fakultas Geografi Universitas Gadjah Mada. 9 halaman. 